\title{
The Virtue of Moderation: A Cross-National Analysis of Exposure to Cross-Cutting Information and Turnout
}

\section{Laia Castro Herrero ${ }^{\mathrm{I}}$ and David Nicolas Hopmann ${ }^{2}$}

\author{
${ }^{\mathrm{I}}$ Department of Communication and Media Research, University of Fribourg, Switzerland; \\ ${ }^{2}$ Centre for Journalism, University of Southern Denmark, Denmark
}

\begin{abstract}
This study examines whether exposure to political disagreement through the media makes citizens more or less likely to vote. Previous research provides mixed and inconclusive results on the mobilizing effects of exposure to cross-cutting, or nonlike-minded, viewpoints. Relying on both 2009 European Election Studies (EES) media content analysis and voter survey covering 27 European Union countries, we construct two measures of cross-cutting news media exposure. We find that the relationship between exposure to cross-cutting information and turnout is nonlinear. While extreme levels of cross-cutting news exposure are negatively associated with turnout, exposure to a moderate degree of non-like-minded news increases the likelihood of voting.
\end{abstract}

At the heart of most theories of democracy is the idea that we base our decisions by weighing pro and con arguments. Recent scholarly debate has raised concerns that citizens, however, increasingly select news media that are biased toward their own political preferences. By doing this, they avoid exposure to arguments with which they disagree. On the demand side, the explosion of media outlets available to citizens today has made it easier than ever before to choose news content that is congruent with one's own ideological preferences. On the supply side, increasing competition in media markets

All correspondence concerning this article should be addressed to Laia Castro Herrero, Department of Communication and Media Research, University of Fribourg, office F304, Bd de Pérolles 90 CH-1700 Fribourg, Switzerland. E-mail: laia.castroherrero@unifr.ch 
makes partisanship an important strategy of product differentiation (Hallin, 2006).

This new media environment has triggered an important scholarly debate on the consequences of current media-consumption patterns (Bennett \& Iyengar, 2008, 2010). Numerous empirical studies have investigated partisan selectivity in news exposure and discussed its link to political knowledge gaps (Prior, 2007), trust in government (Ceron \& Memoli, 20I5), alienation from politics (Nir, 20I2), and electoral participation (Brynin \& Newton, 2003). Overall, these studies indicate that exposure to like-minded news may, as one would expect, reinforce previous political predispositions and encourage participation, especially among more strongly partisan citizens (see also Stroud, 20II).

Do these findings, in reverse, imply a lower turnout as one encounters more non-like-minded news? Surprisingly, to date, only a few empirical studies have dealt with the impact of exposure to conflicting views in the media on political engagement (Barker, I998; Dilliplane, 20II; Wojcieszak, Bimber, Feldman, \& Stroud, 2or6). The reported results have been mixed and inconclusive. In this article, we argue that evidence is limited because assumptions of a linear relationship between exposure to cross-cutting news and turnout are too simplistic. We argue that media exposure to moderate levels of crosscutting information may increase voter turnout, while exposure to extreme levels of non-like-minded information is negatively linked to turnout.

From previous studies on interpersonal communication, we know that exposure to outright oppositional views can trigger political ambivalence (Mutz, 2006), difficulties in processing information (Walton, I968), and demobilization (Klofstad, Sokhey, \& McClurg, 20I2). However, exposure to moderate disagreement, that is, to viewpoints not extremely distant from one's own, can enhance political participation. Moderate cross-cutting exposure has been shown to trigger political learning in anticipation of future social interactions (Eveland, 2004), which, in turn, reinforces certainty that one's political views are solid and well-founded (Festinger, 1954), and encourages political action (Nir, 20I2).

In this study, we build on quantitative data from 2009 European Election Studies (EES) media content and voter-survey studies covering 48,983 news stories, as well as information on political attitudes and the media-usage patterns of 27,079 individuals in 28 European Union (EU) media systems. ${ }^{1}$ By doing this, we go beyond previous single-country studies that focus on the United States. We assess the potential impact of alternative measures of cross-

\footnotetext{
${ }^{1}$ The following European media systems were considered: Austria, Bulgaria, Czech Republic, Denmark, Cyprus, Estonia, Finland, Flanders, France, Germany, Greece, Hungary, Ireland, Italy, Latvia, Lithuania, Luxembourg, Malta, The Netherlands, Poland, Portugal, Romania, Slovenia, Slovakia, Spain, Sweden, United Kingdom, and Wallonia.
} 
cutting news media exposure on turnout. Mixed-effects logistic regression models are built to analyze the extent to which non-like-minded news exposure and turnout are associated and whether variation across countries affects such a correlation. Our results confirm the assumption that this relationship is nonlinear. While exposure to moderate disagreement through the media is positively associated with turnout, outright opposition is negatively correlated with electoral participation. In addition to showing that exposure to media content that is moderately distant from one's own political viewpoints increases the likelihood of voting, we also show that the negative relationship between extreme cross-cutting news exposure and turnout can be counterbalanced by frequent use of news media closer to one's own political views.

\section{Cross-Cutting Exposure and Electoral Participation}

Recent studies on media effects have revealed mixed or inconclusive evidence of the impact of exposure to non-like-minded, or cross-cutting, news on political participation and some of its antecedents. Dilliplane (20II) has shown that cross-cutting news exposure delays time of vote decision and reduces campaign activity, but has no impact on change in turnout from one election to the next. Ceron and Memoli (2015) have found that exposure to non-likeminded information does not play any role on trust in government or hostile media perceptions. Wojcieszak et al. (20I6) showed that cross-cutting exposure has, nevertheless, a marginal indirect impact on intended political participation by triggering anger aimed at contentious political issues, but found no direct impact on participation. Barker (1998) has found some indications of a negative effect from listening to Rush Limbaugh's conservative talk radio show on political participation among liberals in the United States, although the effect is nonsignificant. Conversely, DellaVigna and Kaplan (2007) show that the introduction of Fox News on local cable markets in the United States increased voter turnout, especially in Democratic areas. However, this effect may, in part, be explained by exposure to like-minded news, since, as the authors acknowledge, "the impact of Fox News on voting appears to be due, at least in part, to the mobilization of voters and particularly conservative voters in Democratic-leaning districts" (p. I I 89).

How can we explain the mixed findings from previous research? Such results could stem from divergent methods used to measure cross-cutting news media exposure. Whereas Dilliplane (201 I) relied on self-reported partisan preferences and compared them with audience perception on media outlets' partisanship, DellaVigna and Kaplan (2007) used political organizations' visibility on Fox News as a proxy of its political stance, and tested its effects among viewers in Republican and Democratic districts. Barker (I998) also compared the impact of Limbaugh's show among Republicans and 
Democrats separately, and assigned a conservative slant to the program following previous literature. Wojcieszak et al. (2016) relied on a survey-based experimental design that considered media outlets and their users' supportive/ oppositional stance toward a range of particular political issues.

The aforementioned studies leave room for proposing measures on crosscutting media exposure based on continuous dimensions of political competition other than dichotomous variables on U.S. partisan preferences (i.e., Republican vs. Democrat) or support/opposition toward specific issues, for example, left-right self-placement. Measures of news media's political leanings also can be operationalized by drawing on the actual tone of media content and the partisanship of news outlets' audiences (Ceron \& Memoli, 20 I5; De Vreese \& Tobiasen, 2007; Van Kempen, 2007). We address such methodological challenges by relying on alternative data sources that can account for different scales and political dimensions across different EU countries. Most importantly, we propose two different measures that, unlike previous approaches, allow for gauging how different levels of cross-cutting media exposure have different impacts on electoral participation.

In this article, we argue that there is an association between exposure to cross-cutting news and turnout, but it is nonlinear. Moderate disagreement when exposed to the news may be beneficial for turnout until disagreement reaches a critical threshold, a point at which this positive association becomes negative. Inspired by and departing from Nir's work on social networks (20II), we base the expectation that there is a nonlinear relationship on extant research on interpersonal political communication, political reasoning, social psychology, conflict management, and voting behavior.

Nir (20II) studied the effects of competition among divergent points of view-which implies having some support from others in political discussionsagainst the impact of opposition between one's political preferences and the others'-entailing ideological isolation and no support at all. Her results showed that while being exposed to a mix of oppositional and more congenial opinions is beneficial for participation, outright opposition is indeed detrimental to participation. Guidetti, Cavazza, \& Graziani (2015) found that perceiving disagreement between others' and one's views in political discussions depresses political interest, time taken to make vote decisions, and political participation (political discussion, turnout), while heterogeneity of political views in one's networks can enhance political engagement. Klofstad et al. (2012) similarly reported that general disagreement causes negative effects on political participation and strength-of-preference measures more often than partisan disagreement. According to their reasoning, general disagreement should be seen as more intense disagreement than "only" partisan disagreement. Overall, these studies lend support to the argument that negative effects from exposure to disagreement surface at extreme, not moderate, levels. 
There are numerous reasons why exposure to moderate disagreement can be engaging, while exposure to extreme disagreement can have demobilizing effects. First, comparing diverse viewpoints may trigger information processing and learning. Experiments in the field of political reasoning have shown that being located in heterogeneous social networks makes one more likely to seek out new information with the prospect of future interactions (Eveland, 2004). Furthermore, whereas those in more homogeneous environments encounter congruent messages that easily come to mind (Taber \& Lodge, 2006), those in more noncongenial social networks need to process more challenging information. Accordingly, people who encounter some political disagreement become more able to understand opposing views (Price, Cappella, \& Nir, 2002), differentiate argument quality, pick up relevant information (Levitan \& Visser, 2008), and learn about politics (Guidetti et al., 20I5; Klofstad et al. 20I2; Nir, 20II), making them more politically engaged (Delli Carpini \& Keeter, I996; McLeod et al., I999).

Festinger (I954) also showed that people tend to evaluate the validity of their opinions by comparing them with others' opinions. When these other viewpoints are somemhat distant from their own, but nevertheless close enough to sense that some kind of compromise can be reached, individuals feel "a sense of urgency" to take action and consider alternatives to reduce discrepancies and achieve solid decisions within a group (Walton, I968, p. I I I). As a consequence, it makes sense that those involved in moderate social disagreements feel more satisfied and informed after a discussion (Esterling, Fung, \& Lee, 20I5) than those experiencing extreme ideological differences.

Indeed, individuals exposed to medium levels of disagreement tend to thoroughly examine problems and generate new ideas to overcome conflict, but the relationship between conflict and information processing, as De Dreu \& Beersma (2005) put it, "is curvilinear, so that performance benefits from moderate levels of conflict, but not from either low or high levels of conflict" (p. I08). A high level of disagreement makes a "person's ability to process information and perceive alternatives" decrease (Walton, I968, pp. III-II3) because the overwhelming perception that one is dealing with overly complex matters hinders one's ability to understand the other side and, in turn, depresses willingness to engage in political actions (Wojcieszak et al., 20г6).

Whenever conflicting interests are too distant, individuals are also less willing to accept ongoing bargaining or problem-solving processes, explore and negotiate differences in a flexible way, and reach durable compromises (Brown, I983). Experimental research in social psychology showed that people tend to avoid comparing their own opinions with individuals whose viewpoints are too divergent from their own. Extreme disagreement is unpleasant and, consequently, bypassed, as it raises the possibility that one might have it all wrong (Festinger, I954, p. I28). 
Finally, feelings of distress and uncertainty are pervasive when disagreement is obtrusive, especially among those belonging to groups whose political views find less societal support, such as minorities (McClurg, 2006b). Research on interpersonal communication attests to increasing levels of internal ambivalence, and decreasing political interest and participation, the more disagreement and isolation one encounters (Funk, 200I; Mutz, 2002).

In short, research from various social domains-including interpersonal communication, political reasoning, and conflict management-indicates that some exposure to cross-cutting information may have a beneficial impact on political engagement by triggering political information seeking and processing, enhancing a desire to influence others and take action to reduce conflict, and increasing satisfaction with one's viewpoints, which are finally perceived as solid and wellfounded. Therefore, based on the discussion above, we expect to find the following relationships between cross-cutting news media exposure and voting:

HI: Moderate levels of cross-cutting nems exposure are positively associated with voter turnout.

H2: Extreme levels of cross-cutting nems exposure are negatively associated with turnout.

\section{Data and Methods}

To investigate how levels of exposure to cross-cutting news are related to turnout, we relied on data from the voter survey and the media study of the EES 2009. The EES voter survey includes information on political attitudes, voting behavior, and media use by $27,079 \mathrm{EU}$ citizens $^{2}$ from 27 member states collected during the 3 weeks following the June 2009 European Parliament Elections. The EES team interviewed adults I $8+$ years old either by phone or face-to-face with a standardized questionnaire. ${ }^{3}$ The average response rate across modes was 28.4\% American Association for Public Opinion Research Response Rate I (AAPOR RRI). ${ }^{4}$ The EES media study contains information on media outlets' coverage from 48,983 news stories on TV channels and in newspapers from 27 member states collected during the June 2009 EES. In our analyses, we considered the three leading newspapers and two major TV news programs in each media system. ${ }^{5}$ We drew on a series of multilevel logistic regression models, which allow for and explore between-country variability, with individual turnout

\footnotetext{
${ }^{2}$ The sample per country gathers $\sim_{\mathrm{I}, 000}$ cases (with a minimum of $\mathrm{I}, 000$ cases and a maximum of $\mathrm{I}, 020$ per country). For Belgium, we distinguished between Flanders $\left(N=5^{29}\right)$ and Wallonia $(N=473)$.

${ }^{3}$ Computer-Assisted Telephone Interviewing (CATI) phone interviews were conducted except for nine countries (Bulgaria, Czech Republic, Estonia, Hungary, Latvia, Lithuania, Poland, Romania, and Slovakia), where $70 \%$ of interviews were face-to-face and $30 \%$ by phone.

${ }^{4}$ The response rates vary from $10.9 \%$ (The Netherlands) to $60.3 \%$ (Bulgaria).

${ }^{5}$ Except for Germany (where we had available information on four main TV channels) and Spain (three TV channels).
} 
as the dependent variable and cross-cutting news media exposure as the main independent variable of theoretical interest.

\section{Measures}

Dependent variable. Turnout was constructed as a binary variable, in which I means voted and o means did not vote. Levels of turnout vary, from I $6.63 \%$ in Slovakia to $91 \%$ in Luxembourg. ${ }^{6}$

Independent variables. A first measure of cross-cutting news media exposure $(C M E a)$ was built by calculating the distance between one's political preferences and the average preferences of news media to which an individual is exposed. As a measure of the political stance of individuals, we constructed a variable accounting for the extent to which an individual approves (I) or disapproves $(-I)$ of the national government's record. As a measure of a media outlet's political stance, we used the mean of the national government's positive (I), balanced/mixed (o), or negative ( $-\mathrm{I}$ ) evaluations found in the outlet's news stories (question wording and descriptive statistics of the variables used can be found in Supplementary Appendix A). ${ }^{7}$ Then, the measure of exposure to cross-cutting news was calculated for each individual as the absolute difference between the level of the government's approval and the average evaluation of the government by each media outlet that this individual uses at least once a week, averaged by the number of news media outlets he or she follows (see Supplementary Appendix B for a detailed description of the formula). This measure ranges from o to $2(\mathrm{M}=0.77, \mathrm{SD}=0.67)$, in which 0 stands for no exposure to cross-cutting viewpoints, I for moderate levels, and 2 for the highest level of cross-cutting news media exposure. ${ }^{8}$

This operationalization is not without its shortcomings. First, a two-point scale variable is used to account for citizens' evaluations of the government's record (approve/disapprove). This entails that only more partisan citizens, that is, those who either support or reject governmental actions, could be

\footnotetext{
${ }^{6}$ In election surveys, overreporting of turnout is a common problem (Granberg \& Holmberg, I99I). In the EES 2009 voter survey, the question on turnout was introduced by highlighting the fact that " $\mathrm{A}$ lot of people abstained in the European Parliament elections." While such introductions do not entirely alleviate the problem, previous research has shown that providing respondents with an excuse reduces overreporting (Duff, Hanmer, Park, \& White, 2007).

${ }^{7}$ In total, 3,390 governmental evaluations were coded in all $27 \mathrm{EU}$ member states. We relied on data from the EES 2009 overall sample of TV news media and newspapers in all the countries examined except Wallonia (where evaluations of only one of its newspapers were available), Denmark (evaluations in one newspaper were missing), The Netherlands (one TV news channel could not be considered), and Slovenia (where data for one TV channel were missing). This, however, entailed a minimum loss of information. Citizens who only read or watched those few media outlets that had no evaluations on the government's record were dismissed, reducing the sample $(N=18,842)$ by 5 cases in Slovenia, 42 cases in The Netherlands, 7 cases in Denmark, and ${ }_{5} 5$ cases in Wallonia.

${ }^{8}$ Our methodological approach is grounded on the theoretical assumption that the lowest expression of cross-cutting, or non-like-minded news exposure, is the absence of disagreement, that is, the presence of full agreement, or no experience of disagreement (for similar approaches, see Huckfeldt, Johnson \& Sprague, 2004; Torcal \& Maldonado, 2014).
} 
considered, whereas an average of $9.4 \%$ of cases per country had to be dropped from the sample in the models with CMEa as the main independent variable. Second, evaluations of the governmental record in the EES 2009 content data vary from I6 observations in Luxembourg to 535 observations in news media outlets in Malta. This means that the analysis of the political slant in media outlets was based on varying numbers of evaluations.

To corroborate the findings based on the media-content data, we analyzed exposure to cross-cutting news using an additional measure of cross-cutting exposure based on media consumers' political preferences. This second measure $(C M E b)$ is inspired by previous approaches that used media consumers' partisan preferences to estimate the degree of agreement between political parties and media outlets (Seymour-Ure, I974; Van Kempen, 2007). Similar to $\mathrm{CMEa}, \mathrm{CMEb}$ was constructed by calculating the distance between one's political preferences and the average political views of the news media to which an individual is exposed. However, instead of evaluations of the government's performance, we used the average left-right self-placement of the viewers of each given media outlet as a proxy for its political stance (I I-point scale). Then, our measure of exposure to cross-cutting news was calculated for every individual as the absolute difference between the individual's left-right self-placement and the mean of the left-right placement of the viewers of each media outlet that the individual uses at least once a week, averaged by the number of news media outlets he or she follows (see Supplementary Appendix $\mathrm{B}$ for a detailed description of the formula). ${ }^{9}$ This measure ranges from o to $6.36(M=\mathrm{I} .87, S D=\mathrm{r} .68)$.

Overall, moderate levels of CMEa and CMEb correspond to a mix of exposure to extreme cross-cutting and like-minded views, and also to exposure to media moderately distant to one's viewpoint. The highest values of CMEa and CMEb stand for those individuals exposed to only outright opposition or extreme cross-cutting exposure through news media. Therefore, the measures allow us to analyze the potential impact of fundamentally different types of moderate cross-cutting exposure in news media. They also enable us to gauge different intensities on a continuum (either on an I I-point scale or a 3-point ordinal scale) and different political dimensions (either one issue-attitudes toward national government-or a multidimensional scale-left-right continuum) to account for cross-cutting news in frequent media exposure.

\footnotetext{
${ }^{9}$ As noted by Klofstad et al. (2012), there are several different empirical approaches to operationalizing exposure to non-like-minded views. Most of these approaches differ from each other in their emphasis on either the intensity of disagreement or on the frequency with which one is exposed to opposing viewpoints. In this article, as we are first and foremost interested in the distance between one's own political views and those that one is exposed to through news media, we give equal weight to all media that are being followed at least once a week. This way, we prevent our measure from equating being exposed to extreme ideological disagreement on a weekly basis with more frequent exposure to moderate levels of disagreement.
} 
In our models, we also accounted for left-right self-placement as a control variable, as citizens may be more or less likely to be exposed to cross-cutting news, depending on which side of the political spectrum they are placed. Previous research showed asymmetry in selective exposure, or exposure to consonant bias, between (the United States) conservative and liberal partisans (Iyengar, Hahn, Krosnick, \& Walker, 2008).

Year of birth, level of education, and gender also were included as sociodemographic control variables in our models. Attitudinal variables positively linked to electoral participation, such as political interest (Brady, Verba, \& Schlozman, I995), political knowledge (Delli Carpini \& Keeter, I996), closeness to a party (Bartels, 2000), and external political efficacy (Ginsberg \& Weissberg, 1978), that is, EU efficacy, were considered as control variables. To account for the amount of news media content that one is exposed to (unlike the slant of the news media, which is the main independent variable of interest), frequency of news media exposure (Norris, 2000) also was included in our regression models as a control.

At the contextual level, we controlled for whether voting is compulsory in a given political system (we built on a dummy variable, in which respondents from countries with compulsory voting are assigned " $\mathrm{I}$ " and those without it "o"). We also controlled for whether concurrent elections were held (Franklin, 200I). Simultaneous elections were coded as a dummy variable, in which "I" represents those countries having either local, regional, or national elections at the same time the EU Parliament elections took place (for a similar approach, see Schuck, Vliegenthart, \& De Vreese, 20ı6).

\section{Results}

In a first descriptive step, Figure I depicts the average degree of cross-cutting news exposure in each of the 28 media systems (from 27 countries) considered in this study using the two measures of exposure to cross-cutting news media, namely, CMEa and CMEb. The figure shows that some extent of crosscutting exposure is present everywhere. It also reveals that CMEa-the measure resulting from analyses of governmental evaluations in news content-is hardly correlated with $\mathrm{CMEb}$ - the measure relying on audiences' left-right self-placement (Pearson $r=. \mathrm{I} 7, p<.00 \mathrm{I}$ ). Regardless of the indicator, though, we find that Cyprus (for CMEa $M=0.96, S D=0.38$; CMEb $M=2.60$, $S D=\mathrm{I} .92$ ) and Slovenia (for CMEa $M=\mathrm{I} . \mathrm{I} 3, S D=0.73$; for CMEb $M=2.40, S D=$ I.89) score high, while our measures yield the lowest scores in Estonia (for CMEa $M=0.43, S D=0.82$; for CMEb $M=\mathrm{I} .4 \mathrm{I}, S D=\mathrm{I} .39$ ) and the United Kingdom (for CMEa $M=0.40, S D=0.78$; for CMEb $M=\mathrm{I} .42, S D=\mathrm{I} .55)$. 
Figure I

Average levels of cross-cutting nems exposure in 28 EU media systems. Calculations based on data from the EES 2009

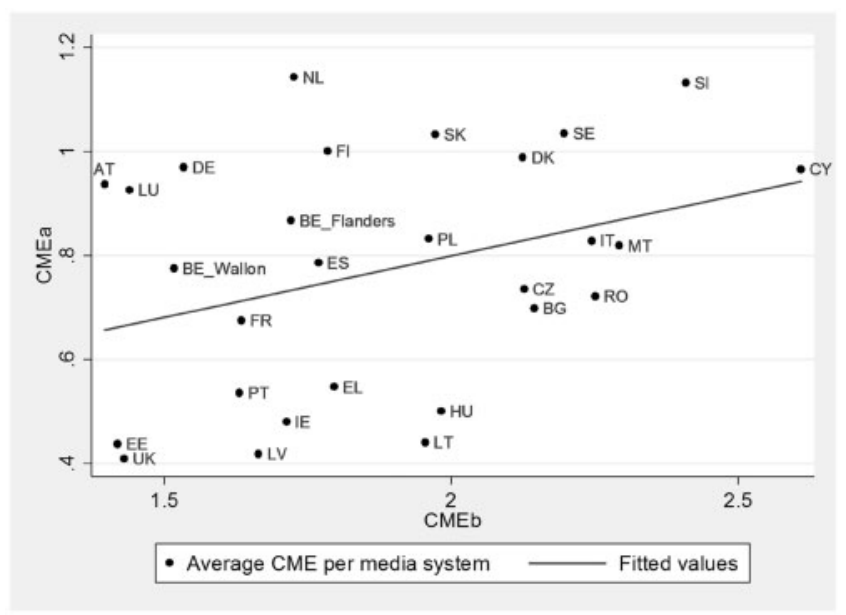

What is the relationship between exposure to cross-cutting news and turnout across countries? We disentangle such association by means of several multilevel logistic regression models as depicted in Table $\mathrm{I}$.

Model Ia in Table $\mathrm{I}$ is a null model without predictors, and its comparison with the following models allows us to confirm that including our main independent variable (CME), together with the rest of the predictors, reduces the amount of unexplained variation in our dependent variable (turnout) remaining at the country level, and improves the models' reproduction of the data. ${ }^{10}$ Model $2 \mathrm{a}-\mathrm{a}$ random intercept model-shows that exposure to crosscutting news is positively correlated to turnout. A nonlinear relationship between exposure to cross-cutting news and turnout is further explored in Model $3^{\mathrm{a}}$ by adding a quadratic term of the main independent variable. Model 3 a reveals a significant curvilinear relationship between the two variables. Compared with Model 2a, the log odds of going to the ballot box and cross-cutting news exposure increase significantly. Moreover, the sign of the coefficient associated with the quadratic term of $\mathrm{CMEa}\left(\mathrm{CMEa}^{2}\right)$ is negative, implying that turnout, as a function of CME, is concave, that is, while some points of the variable may be positively related to turnout, we eventually find a negative correlation for higher scores of cross-cutting news exposure on turnout, as our hypotheses predicted. As a robustness check, Model 4a in

\footnotetext{
${ }^{10}$ The improvement in the goodness of fit of our models is confirmed by the log likelihood (which decreases across models). The Akaike Information Criterion index, which further corrects for the inclusion of predictors in our models, also tends to decrease across the null and the last models, showing that the models fit the data better when further independent variables are included (results not shown here).
} 


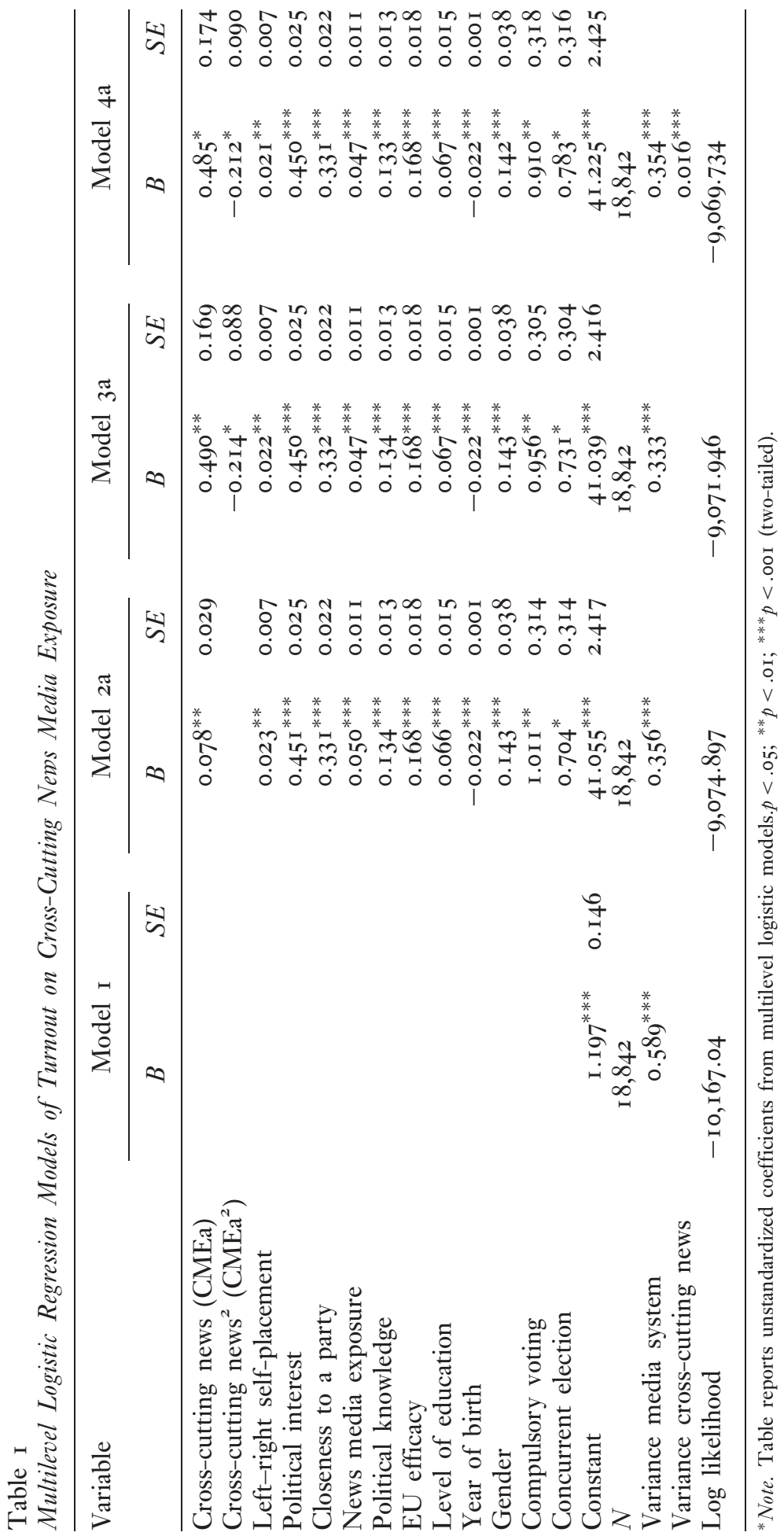


Table $\mathrm{I}$ is a multilevel random slope model that allows the nonlinear effects of cross-cutting news exposure to vary across media systems. The results of this model corroborate the findings in Model $3 \mathrm{a}$. When we let the relationship between cross-cutting news and turnout vary across countries, the nonlinear relationship between CME and electoral participation remains significant.

The replication of the abovementioned models using an additional measure of cross-cutting media exposure-CMEb-as the main independent variable in Table 2 shows a similar trend. Turnout appears to be maximized when the ideological difference between one's left-right self-placement and the leftright positions of the news media outlets that the individual is exposed to are moderate. ${ }^{11}$ Models $\mathrm{b}$ in Table 2 confirm that the linkage between crosscutting exposure-now operationalized using left-right self-placement-and electoral participation follows a non-monotonic pattern, that is, turnout is a concave function of $\mathrm{CMEb}{ }^{12}$

Additionally, the models in Tables $\mathrm{I}$ and 2 show that older and more educated citizens are more likely to vote. Positive relationships are also found for those who are more knowledgeable, politically interested, closer to a party, and consume news. In addition, citizens living in countries where voting is compulsory and where elections other than elections for the European Parliament were held at the same time are more likely to vote, as one would expect.

To assess the magnitude of the potential effects of exposure to crosscutting news on turnout, the two plots in Figure 2 depict the probability of turning out for different values of cross-cutting news exposure ceteris paribus, that is, holding the other variables in our models constant at their means. We clearly can see that the plots depict a parabola, revealing that the probability of voting increases up to a certain level of cross-cutting news exposure $(\mathrm{CMEa}=\mathrm{I} . \mathrm{I} 4 ; \mathrm{CMEb}=3.47),{ }^{13}$ but then starts to decrease. Exposure to moderate disagreement in the media increases the probability of voting by roughly $5 \%$ (for CMEa) and 4\% (for CMEb), compared with low cross-cutting exposure, and extremely disagreeing news content is associated with an average drop of $3 \%$ (for CMEa) and $2.5 \%$ (for $\mathrm{CMEb}$ ), compared with moderate

\footnotetext{
${ }^{11}$ Given that in Models a, we could only rely on more partisan citizens (those who either approve or disapprove of governmental actions), and in Models b, our sample includes cases for which information on $\mathrm{CMEb}$ could be collected $(N=20,040)$.

${ }^{12}$ When excluding nonmedia users from our sample, the nonlinear pattern remained (unstandardized beta coefficients for the quadratic term $\beta=-0.14$ for models with CMEa, $\beta=-0.02$ for models with CMEb), but the significance levels decreased for one of the models $\left(p=.26\right.$ for $\left.\mathrm{CMEa}^{2}\right)$, but not for the other $\left(p=.04\right.$ for $\left.\mathrm{CMEa}^{2}\right)$. We interpret the decrease in significance, compared with the models including nonmedia users, as an indication that like-minded news exposure triggers some mobilizing mechanisms (e.g., reinforcement of previous political predispositions), as extensive research shows (Bennett \& Iyengar, 2008; Brynin \& Newton, 2003; Stroud, 2011), contributing to an attenuation of the curvilinear relationship.

${ }^{13}$ For CMEa, II,952 cases are below this point, with 6,890 above; for CMEb, the cases are 14,760 and 4,082 , respectively.
} 


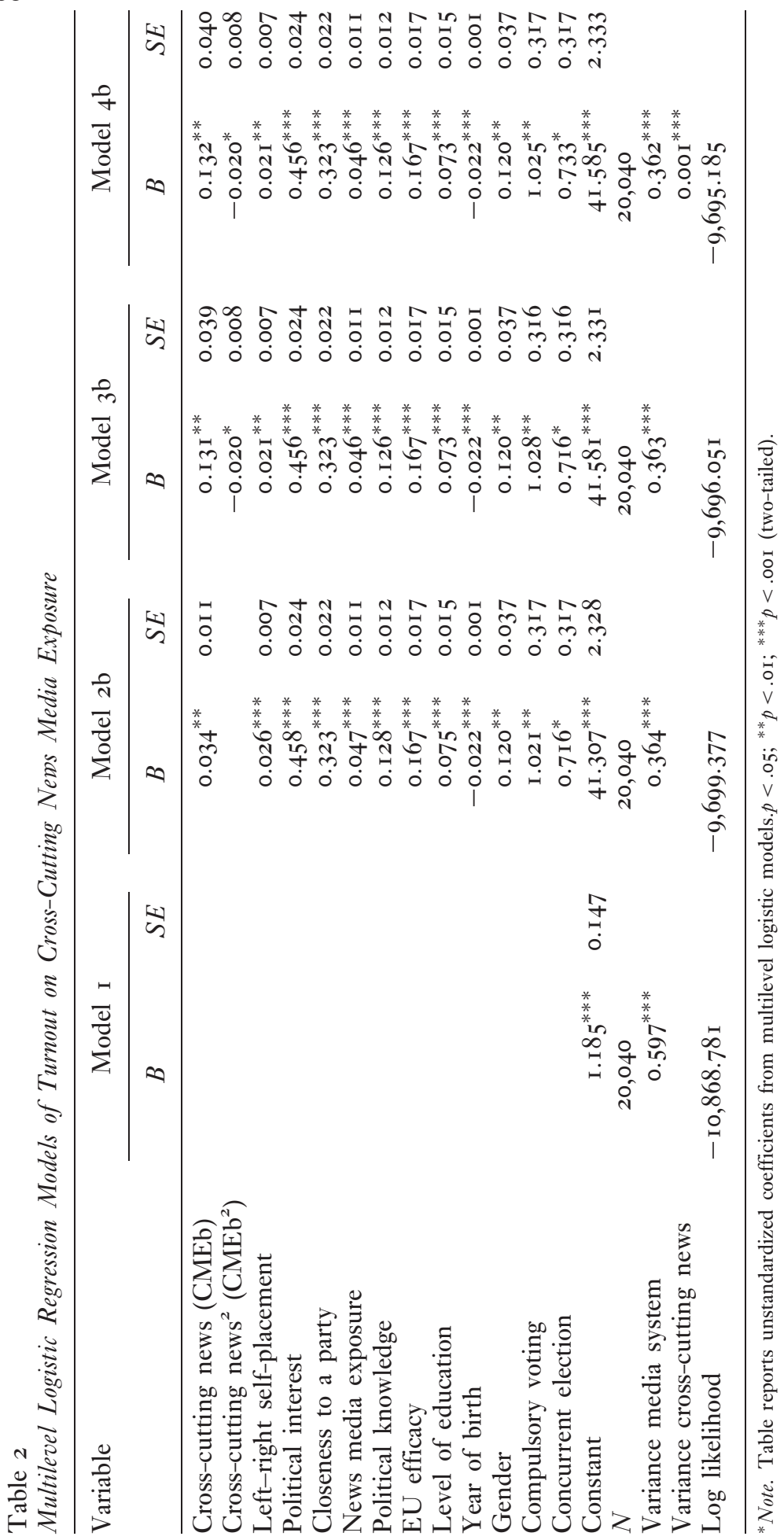


Figure 2

Predicted probability of turnout against cross-cutting nems media exposure (based on Models $4 a$ and $4 b$ in Tables $I$ and 2 )
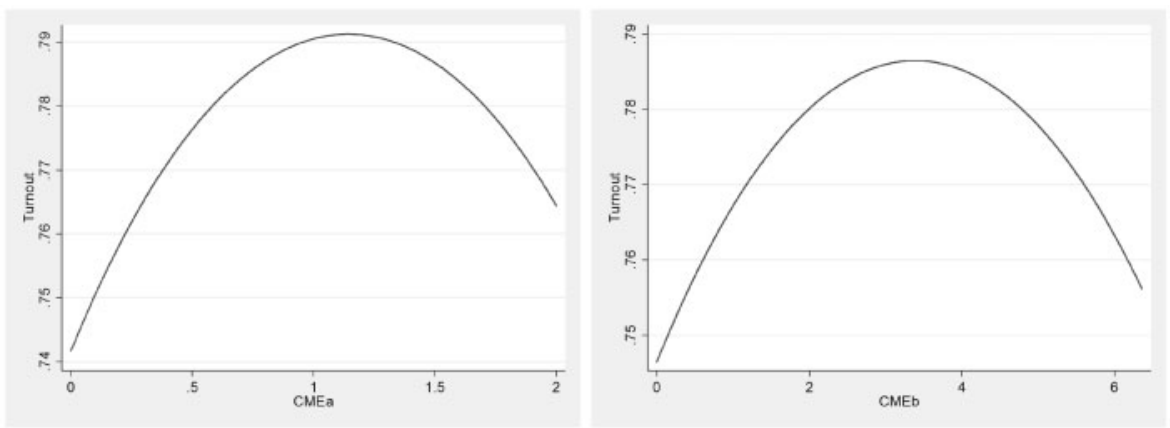

levels of cross-cutting exposure. The magnitude of such predicted probabilities is comparable with that found in former literature for media and interpersonal communication effects on turnout (Huckfeldt, Mendez, \& Osborn, 2004, Kruikemeier, van Noort, Vliegenthart, \& de Vreese, 20I4).

Overall, Figure 2 speaks to two phenomena. First, moderate levels of cross-cutting news media exposure increase the likelihood of voting. Second, such degrees of CME can be reached both by using media moderately distant to one's views and also through exposure to a mixture of pro- and counterattitudinal media outlets. Therefore, as shown in Figure 2, the negative relationship of extreme cross-cutting exposure and electoral participation can be compensated through frequent use of other media outlets closer to one's viewpoints. $^{14}$

Similar trends arise when we let the impact of cross-cutting news exposure vary across media markets. A nonmonotonic pattern between cross-cutting

\footnotetext{
${ }^{14}$ Further analyses with a third additional measure of cross-cutting exposure confirm such trends. This third measure was constructed by subtracting the score of the ideologically most-distant media outlet an individual regularly uses from his or her own left-right placement. The measure was highly correlated with CMEb (Pearson $r=.98, p<.001$ ). As with CMEb, the ideology of an outlet was calculated as the average ideology of those citizens who regularly use it. Unlike CMEb, though, the additional measure scored high in the event of exposure to blatant opposition, regardless of the extent to which one counterbalances such exposure with more like-minded information. By comparing turnout probability plots for different levels of $\mathrm{CMEb}$ and for different levels of this new measure, we were able to discriminate the voting likelihood of those individuals who used media moderately distant from their viewpoints, from that of individuals whose extreme levels of cross-cutting exposure were compensated by like-minded news consumption through other media outlets. The results (not shown) revealed that those using media moderately distant from their views were more likely to vote than those exposed to extreme counter-attitudinal views, even if compensated with closer media. This suggests that whenever one encounters blatantly opposing views, underlying mechanisms conducive to depressing turnout may come into play. With moderation through a combination of extreme and more-like-minded news outlets, the role of extreme cross-cutting exposure in enhancing political uncertainty (Klofstad et al. 2012) may still be in play and partly inhibit more mobilizing mechanisms (e.g., political learning) triggered by exposure to moderate levels of disagreement.
} 
exposure and voting is found across virtually all media markets we used in this study. ${ }^{15}$ For example, an individual living in the United Kingdom exposed to medium levels of CMEa (e.g., holding a negative view of the government and frequently reading information with balanced or mixed evaluations on its record) has, on average, $4 \%$ more probability of casting a vote than an individual exposed to extreme disagreement, compared with a $3.5 \%$ increase for an average citizen living in France. Similarly, a UK citizen exposed to moderate CMEb (i.e., 3.I 8 points away from her own position on the left-right scale) has, on average, a $4 \%$ higher probability of voting than an individual exposed to extreme disagreement, compared with an increase of $2 \%$ for an average individual in France.

\section{Conclusions}

The present study has investigated the effect of cross-cutting news exposure on electoral participation across several political systems, in casu 27 EU countries with 28 media systems. Our findings show evidence of a nonlinear relationship between exposure to political dissonance through media and voting. As our first hypothesis predicted, moderate levels of cross-cutting news exposure are positively associated with electoral participation. Extreme levels of cross-cutting news exposure, however, are negatively related to electoral participation. Therefore, our second hypothesis also finds support.

Overall, this study makes four important contributions to research on partisan selectivity. First, it provides cross-national evidence that in today's Western news media environments, citizens frequently encounter not only like-minded views but also dissonant political viewpoints through the media. Several studies have documented growing levels of like-minded news exposure and partisan polarization among media audiences (Iyengar \& Hahn, 2009; Stroud, 20II). In a similar vein, some others have argued that current news media environments (Goldman \& Mutz, 20II) and news media consumption patterns (Bennett \& Iyengar, 2008) contribute to reinforcing people's political predispositions. A major area of such studies focuses on the U.S. context (see also Mutz, 2006), in which the presence of partisan cable news outlets (Prior, 2007), the absence of a strong public service broadcaster with adhered values of representativeness and political balance (McQuail, I992), and a two-party system make it easier for citizens to access information in line with their political views (Wessler \& Rinke, 20I4). Our study complements U.S. research by investigating cross-cutting exposure in 28 European media markets, where power-concentrating systems are rare exceptions and the presence of publicservice TV is more salient, with a spillover effect on commercial channels

\footnotetext{
${ }^{15}$ For CMEa, Estonia turned out to be an outlier, in which the relationship between exposure to political dissonance and turnout is invariably positive.
} 
(Reinemann, Stanyer, \& Scherr, 2017). Overall, we show that Europeans frequently encounter at least some cross-cutting news. Second, our analyses also reveal that being exposed to dissonant views through the media significantly predicts voter turnout. Unlike previous studies (Barker, I998; Dilliplane, 20II), our findings show that exposure to political dissonance may have a positive effect on electoral participation. This divergence can be explained because of the nonlinear nature of such an association, that is, the relationship between exposure to cross-cutting information and turnout describes a parabola, in which, at one point, exposure to disagreement becomes too much for those who experience it. Third, our study shows that partisan media exposure does not necessarily entail trading deliberation for participation. It is not only people who engage in like-minded news exposure who are more likely to vote but also citizens who frequently expose themselves to viewpoints different from their own. Fourth, we find that the potential negative impact of extreme cross-cutting exposure on turnout can be diminished by frequent use of lessdivergent news media.

These findings are in line with results by previous experimental and survey research on social disagreement in political discussions (Nir, 20II). As with interpersonal communication, citizens appear to be better served by the media when either their frequently used media outlet or their media diet provides them with an ensemble of pro and con arguments, instead of onesided depictions of political issues.

Our study is not without its shortcomings. First, our dependent variable (turnout) relies on data from European Parliament (EP) elections. Although this enables equivalence in analyzing electoral participation across countries, EP elections have been considered by an extensive strand of literature as second-order national elections (Marsh, I998; Reif \& Schmitt, I980). Some of the central implications of EP elections being less important than national elections are that people tend to vote in smaller numbers in the former than in the latter, and that they do so on the basis of their national political preferences and government performance. This does not necessarily add a limitation to our study, but makes our results potentially more significant. As one of our indicators of CME is based on individuals' evaluations of national government (CMEa), we would expect cross-cutting exposure to have even greater effects on turnout in national than in EP elections. In this context, one may discuss how warranted it is to use evaluations of national government in the context of EP elections. While a recent strand of literature has shown that EU issues influence voting in European elections, this research still showed that voting behavior in EP elections is heavily influenced by national political considerations (De Vries, Van der Brug, Van Egmond, \& Van der Eijk, 20 I ; Hobolt \& Wittrock, 20II). Furthermore, our study also relied on further CME measures that stem from a powerful predictor of EU vote choice: self-placement on 
the left-right spectrum (Hobolt \& Wittrock, 20II), which is considered a control variable in our models and contributes to correcting for potential distortions because of extreme ideologies overlapping with attitudes against the European project (e.g., an extreme leftist individual exposed to anti-EU viewpoints from his or her extreme-rightist media diet).

Second, although EES 2009 considers values of the left-right scale as equivalent indicators of ideological differences across EU countries, the leftright scale may convey different meanings in different countries (Huber, I989). Also, some newer democracies in Central and Eastern Europe have high levels of electoral volatility and party system instability - which may render self-placement on the classic left-right scale more challenging. Nevertheless, we argue that as we can distinguish between parties using the average left-right self-placement of their voters in such countries, our scale is a useful measure to assess differences between media outlets' ideological leanings in any given system. Furthermore, the two measures of CME, although significantly different, show similar trends when associated with turnout.

Third, none of the models analyzed in the article can resolve the direction of causality, as they rely on cross-sectional data. We cannot determine empirically whether cross-cutting news exposure triggers turnout, or if it is citizens' willingness to participate that leads to them seeking other viewpoints. Panel survey data or experimental evidence could help identify causality and confirm the trend found in this study. That said, our results hold true using two distinct measures of cross-cutting exposure and relying on two different methods of data collection-content and survey data-across $27 \mathrm{EU}$ countries. Therefore, we go beyond previous case studies and gain analytical insight into the nonlinear relationship of media exposure and turnout, which remains significant after controlling for both country-level idiosyncratic factors and individual variables.

Fourth, by relying on self-reported cross-cutting exposure, we are only accounting for those who willingly self-selected news information that conflicts with their political views. Though this paints a more reliable picture of the effects that CME may have on actual media users, our study does not account for the role of motivation, ability, and opportunity that may lie behind exposure to politically dissimilar views (for an overview of the impact of such triads on political sophistication and media exposure, see Cooper \& Tang, 2009; Luskin, 1990). That said, recent experimental research finds no difference in the impact of like-minded news media exposure on intended voter participation and polarization between self-selected and experimentally assigned news users (Trilling, Van Klingeren, \& Tsfati, 20ı6; Wojcieszak et al., 20I6).

Further research should empirically address the underlying mechanisms that may mediate the relationship between cross-cutting exposure and turnout. For 
instance, we learned from previous literature that the need to seek new information can be triggered by cross-cutting media exposure and can be conducive to political mobilization. Likewise, exploring mechanisms such as ambivalence (Mutz, 2002) or delayed decisions on whom to vote for (Dilliplane, 201 I) may help explain the eventually negative effect on turnout from extreme levels of exposure to cross-cutting news through media. Another research avenue worth exploring is investigating the extent to which certain individual characteristicssuch as opinion extremity, attitude strength, or holding minority views - can moderate the relationship between exposure to hostile or uncongenial news information and participation (Wojcieszak, 20II, 2015).

In sum, the ability of cross-cutting exposure to mobilize citizens to vote is contingent on the extent to which media provide us with a balanced diet of pros and cons. By showing that moderate political disagreement is consistently and positively associated with turnout, we make a novel contribution to the debate on the impact of partisan news exposure on political behavior and shed light on the effects that different levels and types of cross-cutting news media exposure may have on electoral participation.

\section{Acknowledgments}

We thank Devra Moehler for her valuable comments and suggestions to a previous version of this paper.

\section{Supplementary Data}

Supplementary Data are available at IJPOR online.

\section{References}

Barker, D. C. (1998). The talk radio community: Nontraditional social networks and political participation. Social Science Quarterly, 79, 26I-272.

Bartels, L. M. (2000). Partisanship and voting behavior, I952-1996. American Fournal of Political Science, 44, 35-50. doi: 10.2307/2669291

Brady, H. E., Verba, S., \& Schlozman, K. L. (I995). Beyond SES: A resource model of political participation. American Political Science Reviem, 89, 27I-294. doi: $10.2307 / 2082425$

Bennett, W. L., \& Iyengar, S. (2008). A new era of minimal effects? The changing foundations of political communication. Fournal of Communication, 58, 707-73I. doi: IO.I I I I/j. I 460-2466.2008.004Io.x

Bennett, W. L., \& Iyengar, S. (2010). The shifting foundations of political communication: Responding to a defense of the media effects paradigm. Fournal of Communication, 60, 35-39. doi: Io.III I/j.I460-2466.2009.0I47I.X 
Brown, L. D. (I983). Managing conflict at organizational interfaces. Reading: Addison Wesley Publishing Company.

Brynin, M., \& Newton, K. (2003). The national press and voting turnout: British general elections of 1992 and I997. Political Communication, 20, 59-77. doi:Io.1o8o/ I0584600390 72347

Ceron, A., \& Memoli, V. (2015). Trust in government and media slant: A crosssectional analysis of media effects in twenty-seven European countries. The International Fournal of Press/Politics, 20, 339-359. doi: Iо. I I77/I940 I6 I 2 I 5572634 Cooper, R., \& Tang, T. (2009). Predicting audience exposure to television in today's media environment: An empirical integration of active-audience and structural theories. Fournal of Broadcasting and Electronic Media, 53, 400-4I8.

De Dreu, C. K., \& Beersma, B. (2005). Conflict in organizations: Beyond effectiveness and performance. European Fournal of Work and Organizational Psychology, I4, I05-I I7. doi: 10.1080/13594320444000227

De Vreese, C., \& Tobiasen, M. (2007). Conflict and identity: Explaining turnout and anti-integrationist voting in the Danish 2004 elections for the European parliament. Scandinavian Political Studies, 30, 87-I I4. doi: Io. I I I/j.I467-9477.2007.00I74.x

de Vries, C. E., Van der Brug, W., Van Egmond, M. H., \& Van der Eijk, C. (20I I). Individual and contextual variation in EU issue voting: The role of political information. Electoral Studies, 30, I6-28. doi: го.гог6/j.electstud.20г0.09.022

DellaVigna, S., \& Kaplan, E. (2007). The Fox News effect: Media bias and voting. The Quarterly Fournal of Economics, I22(3), II87-I234.

Delli Carpini, M. X., \& Keeter, S. (I996). What Americans knom about politics and why it matters. New Haven, CT: Yale University Press.

Dilliplane, S. (20II). All the news you want to hear: The impact of partisan news exposure on political participation. Public Opinion Quarterly, 75, 287-316. doi: Io. I093/poq/nfroo6

Duff, B., Hanmer, M. J., Park, W. H., \& White, I. K. (2007). Good excuses: Understanding who votes with an improved turnout question. Public Opinion Quarterly, 7I, 67-90.

Esterling, K. M., Fung, A., \& Lee, T. (2015). How much disagreement is good for democratic deliberation? Political Communication, 32, 529-55 I doi:Io.1o93/poq/ nflo45

Eveland, W. P. (2004). The effect of political discussion in producing informed citizens: The roles of information, motivation, and elaboration. Political Communication, 2I, I77-I93. doi: Io.1080/10584600490443877

Festinger, L. (1954). A theory of social comparison processes. Human Relations, 7 , I I 7-I 40. doi: Iо. I I 77/ оо I 872675400700202

Franklin, M. N. (200I). How structural factors cause turnout variations at European parliament elections. European Union Politics, 2, 309-28.

Funk, C. L. 200I. What's Not to Like? Explaining Public Disinterest in Politics. Paper presented at the Annual Meetings of the Midwest Political Science Association, April I9-22, 200I, Chicago, IL.

Ginsberg, B., \& Weissberg, R. (I978). Elections and the mobilization of popular support. American Fournal of Political Science, 22, 3I-55. doi: 10.2307/2 I 10668 
Goldman, S. K., \& Mutz, D. C. (20II). The friendly media phenomenon: A crossnational analysis of cross-cutting exposure. Political Communication, 28, 42-66. doi: I0.1080/10584609.2010.544280

Granberg, D., \& Holmberg, S. (I99I). Self-reported turnout and voter validation. American Fournal of Political Science, 35, 448-459. doi: 10.2307/21 II370

Guidetti, M., Cavazza, N., \& Graziani, A. R. (2015). Perceived disagreement and heterogeneity in social networks: Distinct effects on political participation. The Fournal of Social Psychology, I56, 222-242. doi:10.1080/00224545.2015.1095707

Hallin, D. C. 20o6. The Passing of the 'High Modernism' of American Journalism Revisited. Political Communication Report, I6(I). Retrieved from http://frank. mtsu.edu/ pcr/I6oI_2005_winter/commentary_hallin.html.

Hobolt, S. B., \& Wittrock, J. (20II). The second-order election model revisited: An experimental test of vote choices in European Parliament elections. Electoral Studies, 30, 29-40. doi: го. Ior6/j.electstud.2010.09.020

Huber, J. D. (1989). Values and partisanship in left-right orientations: Measuring ideology. European Fournal of Political Research, I7, 599-62I. doi:Io.IIII/j.I4756765.1989.tboo209.x

Huckfeldt, R., Mendez, J. M., \& Osborn, T. (2004). Political disagreement: The survival of diverse opinions within communication networks. Cambridge: Cambridge University Press.

Iyengar, S., \& Hahn, K. S. (2009). Red media, blue media: Evidence of ideological selectivity in media use. Fournal of Communication, 59, I9-39. doi: Io.IIII/j.I4602466.2008.0I402.X

Iyengar, S., Hahn, K. S., Krosnick, J. A., \& Walker, J. (2008). Selective exposure to campaign communication: The role of anticipated agreement and issue public membership. The Fournal of Politics, 70, I86-200. doi: го.1017/s0022381607080139

Klofstad, C. A., Sokhey, A.E., \& McClurg, S.D. (2012). Disagreeing about disagreement: How conflict in social networks affects political behavior. American fournal of Political Science, 57, I20-I34. doi: ro.1 II /j.I540-5907.2012.00620.x

Kruikemeier, S., van Noort, G., Vliegenthart, R., \& de Vreese, C. H. (2014). Unraveling the effects of active and passive forms of political Internet use: Does it affect citizens' political involvement? New Media and Society, I6, 903-920 doi: I. I I 77 /I 46 I 4448 I 3495 I63

Levitan, L. C., \& Visser, P.S. (2008). The impact of the social context on resistance to persuasion: Effortful versus effortless responses to counter-attitudinal information. Fournal of Experimental Social Psychology, 44, 640-649. doi:Io.roi6/ j.jesp.2007.03.004

Luskin, R. C. (I990). Explaining political sophistication. Political Behavior, I2, 33I36I. doi:I0.1007/BFoog92793

Marsh, M. (1998). Testing the second-order election model after four European elections. British Fournal of Political Science, 28, 59I-607.

McClurg, S. D. (2006b). Political disagreement in context: The conditional effect of neighborhood context, disagreement and political talk on electoral participation. Political Behavior, 28, 349-366. doi: I0.1007/si I 109-006-9015-4

McLeod, J. M., Scheufele, D. A., Moy, P., Horowitz, E. M., Holbert, R. L., Zhang, W. \& , \& Zubric, J. (I999). Understanding deliberation the effects of discussion 
networks on participation in a public forum. Communication Research, 26, 743-774. doi: го. I 77 /009365099026006005

McQuail, D. (I992). Media performance: Mass communication and the public interest. London: Sage.

Mutz, D. C. (2002). The consequences of cross-cutting networks for political participation. American Fournal of Political Science, 46, 838-855. doi: 10.2307/3088437

Mutz, D. C. (2006). Hearing the other side: Deliberative versus participatory democracy. Cambridge, UK: Cambridge University Press.

Nir, L. (20II). Disagreement and opposition in social networks: Does disagreement discourage turnout? Political Studies, 59, 674-692 doi: Iо.гігі/j.I467$9248.2010 .00873 \cdot \mathrm{x}$

Nir, L. (2012). Public space: How shared news landscapes close gaps in political engagement. Fournal of Broadcasting and Electronic Media, 56, 578-596. doi: Io. Io80/o8838I 5 I.20I2.732 I 45

Norris, P. 2000. A virtuous circle: Political communications in postindustrial societies. New York, NY: Cambridge University Press.

Price, V., Cappella, J. N., \& Nir, L. (2002). Does disagreement contribute to more deliberative opinion? Political Communication, I9, 95-II2 doi:Io.Io80/ I05846002317246506

Prior, M. (2007). Post-broadcast democracy: How media choice increases inequality in political involvement and polarizes elections. New York, NY: Cambridge University Press.

Reif, K., \& Schmitt, H. (I980). Nine second-order national elections. A conceptual framework for the analysis of European election results. European Fournal for Political Research, 8, 3-44. doi: Io. I I I/j.I475-6765. I980.tboo737.x

Reinemann, C., Stanyer, J., \& Scherr, S. (20I7). Hard and soft news. Comparing Political fournalism, I3I, I3I-I49.

Schuck, A. R., Vliegenthart, R., \& De Vreese, C. H. (2016). Who's afraid of conflict? The mobilizing effect of conflict framing in campaign news. British fournal of Political Science, 46, I77-I94. doi: ro. Ior7/Sooo7I23413000525

Seymour-Ure, C. (1974). The political impact of mass media. London: Constable.

Stroud, N. J. (20II). Niche nems: The politics of nems choice. New York: Oxford University Press.

Taber, C. S., \& Lodge, M. (2006). Motivated skepticism in the evaluation of political beliefs. American Fournal of Political Science, 50, 755-769. doi: Io. I I I/j.I5405907.2006 .002 I 4.X

Torcal, M., \& Maldonado, G. (20I4). Revisiting the Dark Side of Political Deliberation The Effects of Media and Political Discussion on Political Interest. Public Opinion Quarterly, 78, 679-709.

Trilling, D., Van Klingeren, M., \& Tsfati, Y. (2016). Selective exposure, political polarization, and possible mediators: Evidence from the Netherlands. International Fournal of Public Opinion Research, 29, I89-2г3. doi: го.г093/ijpor/edwoo3

Van Kempen, H. (2007). Media-party parallelism and its effects: A cross-national comparative I5 Study. Political Communication, 24, 303-320. doi:Io.1o8o/ г 058460070 I 47 I 674 
Walton, R. E. (1968). Interpersonal Peacemaking: Confrontations and Third Party Interventions. Cambridge, Massachussets: Harvard University Graduate School of Business Administration.

Wessler, H., \& Rinke, E. M. (20I4). Deliberative performance of television news in three types of democracy: Insights from the United States, Germany, and Russia. Fournal of Communication, 64, 827-85I. doi: Io.IIII/jcom.I2II5

Wojcieszak, M. (201 I). Pulling toward or pulling away: Deliberation, disagreement, and opinion extremity in political participation. Social Science Quarterly, 92, 207225. doi: Io.IIII/j.I540-6237.20I I.00764.x

Wojcieszak, M. (2015). Hostile public effect: Minority status mobilizing political participation. International Fournal of Public Opinion Research, 29, 46-69. doi: I0.1093/ ijpor/edvo 6

Wojcieszak, M., Bimber, B., Feldman, L., \& Stroud, N. J. (2016). Partisan news and political participation: Exploring mediated relationships. Political Communication, 33, 24I-260. doi: 10.1080/I0584609.2015.105 I608

\section{Biographical Notes}

Laia Castro-Herrero is research and teaching associate at the Department of Communication and Media Research at the University of Fribourg. She received her MA in Political Communication from Universitat Autònoma de Barcelona in 2009 .

David Nicolas Hopmann is a professor (WSR) at the Centre for Journalism at the University of Southern Denmark. He received his $\mathrm{PhD}$ in Political Science from the University of Southern Denmark in 2009. 